\title{
Colour contribution to children's wayfinding in school environments
}

\author{
Elif Helvacıoğlu, Nilgün Olguntürk* \\ Department of Interior Architecture and Environmental Design, Faculty of Art, Design and Architecture, Bilkent University, 06800 Bilkent, Ankara, Turkey
}

\section{A R T I C L E I N F O}

\section{Available online 19 July 2009}

Keywords:

Wayfinding

Colour

School environment

\begin{abstract}
A B S T R A C T
The purpose of this study was to explore the contribution of colour to children's wayfinding ability in school environments and to examine the differences between colours in terms of their remembrance and usability in route learning process. The experiment was conducted with three different sample groups for each of three experiment sets differentiated by their colour arrangement. The participants totalled 100 primary school children aged seven and eight years old. The study was conducted in four phases. In the first phase, the participants were tested for familiarity with the experiment site and also for colour vision deficiencies by using Ishihara's tests for colour-blindness. In the second phase, they were escorted on the experiment route by the tester one by one, from one starting point to one end point and were asked to lead the tester to the end point by the same route. In the third phase, they were asked to describe verbally the route. In the final phase, they were asked to remember the specific colours at their correct locations. It was found that colour has a significant effect on children's wayfinding performances in school environments. However, there were no differences between different colours in terms of their remembrances in route finding tasks. In addition, the correct identifications of specific colours and landmarks were dependent on their specific locations. Contrary to the literature, gender differences were not found to be significant in the accuracy of route learning performances.
\end{abstract}

(c) 2009 Elsevier Ltd. All rights reserved.

\section{Introduction}

The difficulty of navigating in unfamiliar environments suggests the need to support it by using appropriate environmental design elements such as layout, landmarks and signage in real and virtual spaces. An additional tool for navigation is the use of colour, which is very important as it can help a person to develop a mental map of the architectural environment [1]. However, there is only a limited number of studies available on the impact of colour on human wayfinding ability.

Adults develop their sense of spatial learning over a period of years, and this process begins in childhood. By the age of seven, children start to understand their environment, and at eight they remember events and places at the beginning and end of a route [2]. However, children need more support than adults for navigating themselves in an environment and colour can help to provide this. Existing studies generally focus on children's pointing task abilities [3,4] and spatial memories [5-7], but not on colour.

School becomes a dominant force in the life of children by the time of pre-schooling and primary schooling [8]. Children have their first experiences in school and these experiences can affect

\footnotetext{
* Corresponding author. Tel.: +903122902429.

E-mail address: onilgun@bilkent.edu.tr (N. Olguntürk).
}

children's psychology either positively or negatively. Providing legible spaces for children may contribute to their psychological well-being. The nature and quality of the environment are also influential on how and what young students learn. This study highlights the effects of colour on children's route learning performances and the differences between colours in terms of their remembrance and usability in the process of route learning.

\section{Children's wayfinding and colour}

Finding one's way around is a purposeful and motivated activity [9]. This activity is defined by many studies as wayfinding. Wayfinding is the process of reaching a destination, whether in familiar or unfamiliar environments [10], and is defined as "the organization and communication of our dynamic relationship to space and the environment" ([11], p. 43). It is an activity that requires complete involvement with the environment [12]. During this involvement, wayfinders try to understand the setting they are in, with the information they have obtained. Wayfinding design involves communication of information to help users of the environment find their destinations, understand where they are and maintain their sense of orientation [13].

Awareness of place develops very rapidly with age [14,15]. As their age increases, young children acquire more information about places and their ability to depict changes in space improves. 
Children around the age of eight start to understand the world in which they move as a metric system, a two-dimensional structure that remains constant [16]. Ten year old children display more confidence while walking, with knowledge of their environment [17]. Landmarks have an important role in the development of children's orientation abilities and spatial cognition performance $[5,18]$. The existence of landmarks influences wayfinding performance of adults and children in the same way.

Route knowledge, as a part of wayfinding, means the sequential knowledge of routes between places that are linked to landmarks $[19,20]$. People acquire route knowledge for finding a way back, finding a short cut and making a detour. For finding the same way back, people have to remember not only the objects that were passed through but also the places where they made turns and changes of direction [21]. Children learn some things about the order of events along a route and route reversal performance depends upon memories of those events. For children events at the beginning and at the end of a tour are more distinctive than events in the middle [2].

Users' successful wayfinding abilities depend on the availability of environmental information. Because of its easy manipulation in a variety of materials, colour is an ideal design element for creating environmental information that supports users' wayfinding abilities [22]. Colour can help develop the definition of an architectural environment by reinforcing the hierarchy of spaces and landmarks, and by clarifying the destinations and prominent features. It can also help to aid the understanding of the form of a building and help to act as signage in that building [1]. Colour also plays a significant role during encoding and recognition processes. It helps to improve visual memory of images in a building environment [23].

The structuring of space through colouring helps in the same manner both children of school age and adults to find their way around [6]. Children need their environment to be interesting, and young children make associations with colour and shapes rather than form. Therefore, using colour in their environment can provide visual interest to supply maximum efficiency in navigation by providing visual dominancy in key building elements [1], can improve children's wayfinding and spatial orientation abilities in their environment, and specifically with warm hues and bright accents can improve children's sensory stimulation [22].

\section{The experiment}

The hypotheses of this study are:

1. There is a significant effect of colour on children's route learning ability.

2. There is a significant effect on children of different hues of colour, which can contribute to their route learning ability.

3. There is a significant relationship between the colours and their locations in route learning.

4. There is a significant effect of gender in children on route learning ability.

\subsection{Sample group}

The sample group was from students enrolled in the Ankara University Private High School. For the experiment, children were chosen by stratified quota sampling on the basis of age, gender and familiarity factor. All participants were primary school first graders, aged seven and eight years old. Only the participants who were unfamiliar to the building were selected. A total of 100 children participated to the tests, where a third of this sample group was used for each test ( 32 children for experiment set 1, 34 children for experiment set 2 and 34 children for experiment set 3).

\subsection{Selecting the route}

Before the experiment, the layout of the building was analysed and a route from point $X$ (main entrance of the building) to point $Y$ (the biology laboratory) was specified for the experiment, as shown in Figs. 1-3. Six decision points, that is where students would make a decision to orient themselves through the major paths and floors, were identified within that route and six boxes were placed at those decision points before the experiment.

\subsection{Establishing the landmark boxes}

The boxes were designed in a rectangular form and were positioned in a vertical direction. They were perceived from different places and distances in the corridor and this was important for the visibility and usability of the boxes as landmarks. They were sized $25 \times 60 \mathrm{~cm}^{2}$ in order to maintain the proportional values with the height of seven and eight year old children $(123.5 \mathrm{~cm}$ is the average height of seven and eight year old children). It was also important that the boxes did not physically interrupt the pathway. The positioning is apparent in Figs. 4 and 5.

\subsection{Definition of colour sets of the experiment}

Natural colour system (NCS) was used in specification and selection of colours. Basic to the NCS is the recognition of the three opponent pairs of psychological primaries involved in colour vision, namely white and black, red and green, and yellow and blue, derived from the three classes of cones identified in the retina ([24], p. 12, 133-37). These opponent pairs define six natural colour sensations, which are white $(W)$, black ( $S$, for the Swedish word "svart"), red (R), green $(G)$, yellow $(Y)$ and blue $(B)$. The last four are the unitary hues, such as yellow that is neither greenish nor reddish, and green that is neither bluish nor yellowish (as may be seen in Fig. 6). All other hues are recognised as mixtures of two unitary hues; for example, greenish yellows, reddish yellows, yellowish reds, bluish reds, etc. ([24], p. 133-37). These hues are arranged in a circle with nine intermediate steps between each, totalling 40 hues. Then, for each hue, a triangular chart is developed showing the pure hue and its relationship to white and black, as in Fig. 7 ([25], p. 205). The NCS describes the formal basic elements of the colour language and it provides the ability to identify characteristic similarities and relations between colours [26].

It is appropriate here also to mention the Munsell colour system, which represent different samplings of essentially the same colour space with the NCS. The Munsell system identifies the surface colours by three quantities: hue, chroma and value. There are ten hue ranges in the hue circle of the Munsell system, which appear in the order (clockwise): red, yellow red, yellow, green yellow, green, blue green, blue, purple blue, purple and red purple. Munsell value is designated on a scale from 0 to 10 and is an indication of the lightness of perceived colour. Munsell chroma of a colour sample is defined as its difference from neutral grey of the same value. Munsell chroma is often considered to be the perceived saturation. 


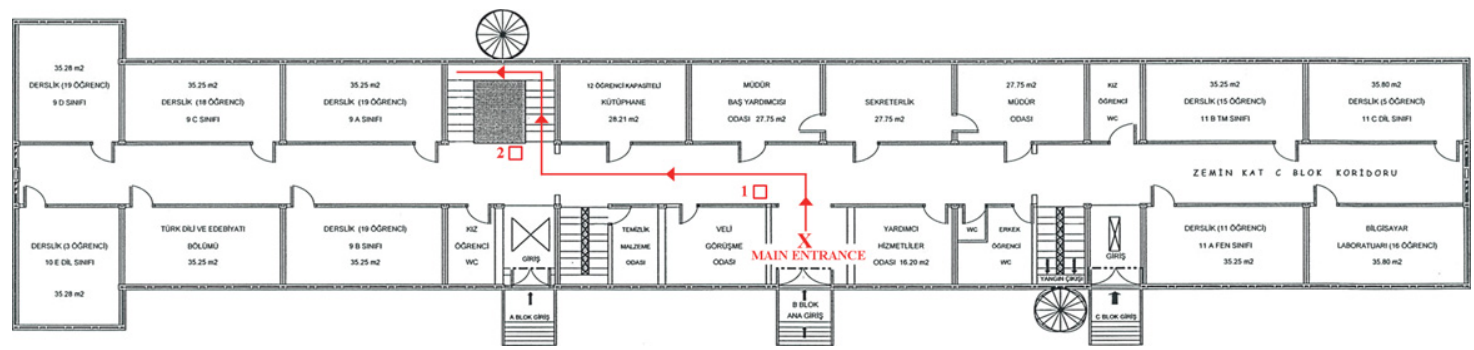

Fig. 1. Ground floor plan of the school building with selected route.

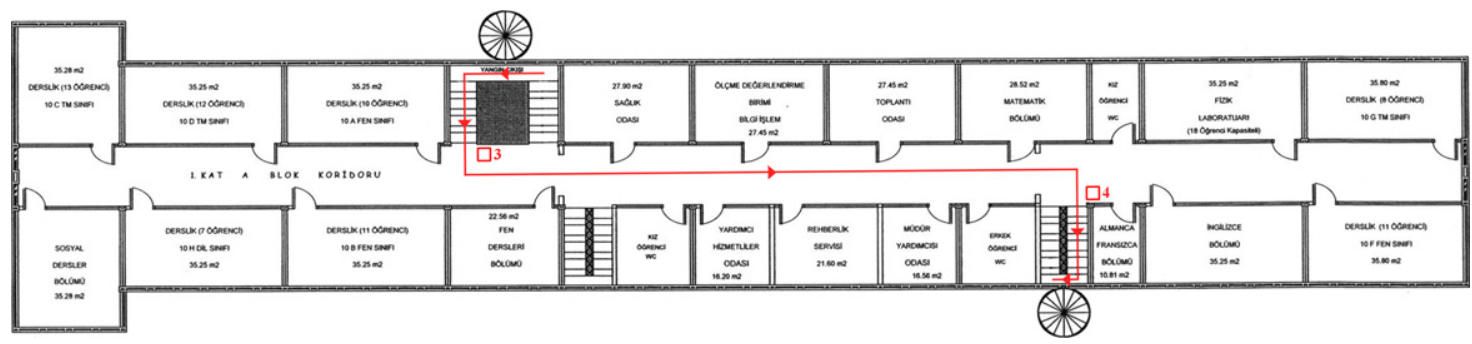

Fig. 2. First floor plan of the school building with selected route.

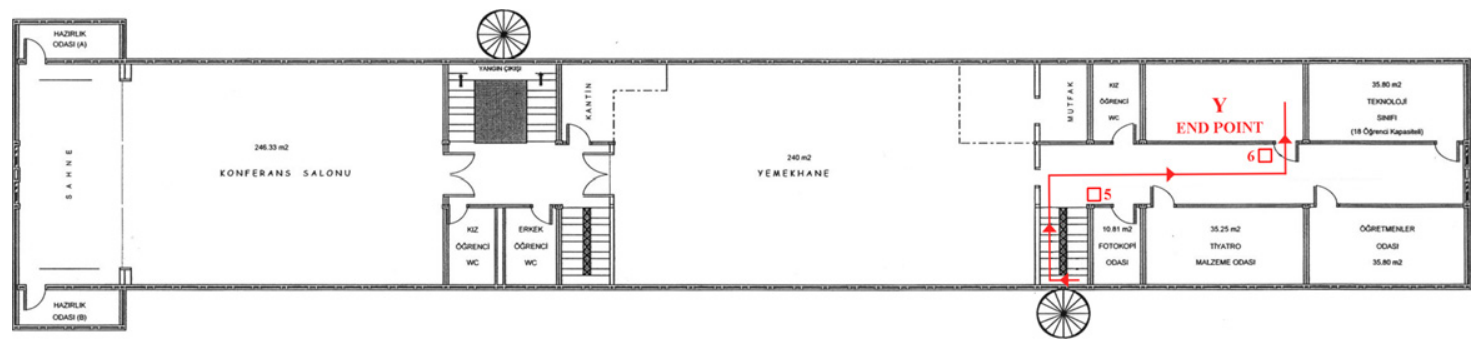

Fig. 3. Second floor plan of the school building with selected route.

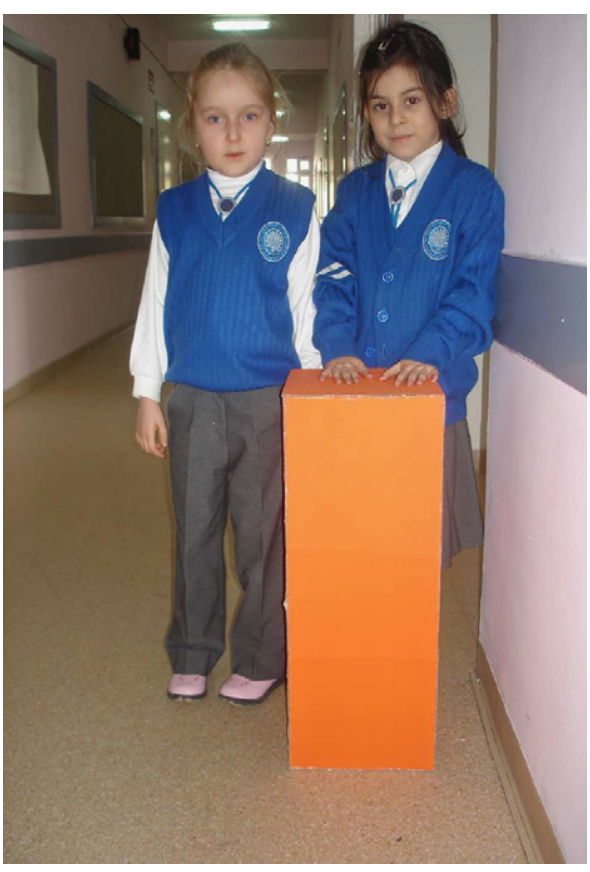

Fig. 4. View of the box with a seven-year-old female child.

In experiments concerning colour, it is important to use the colours with the same lightness (value) and 'chromaticness' (chroma, saturation) for controlling the variables. The aim is to

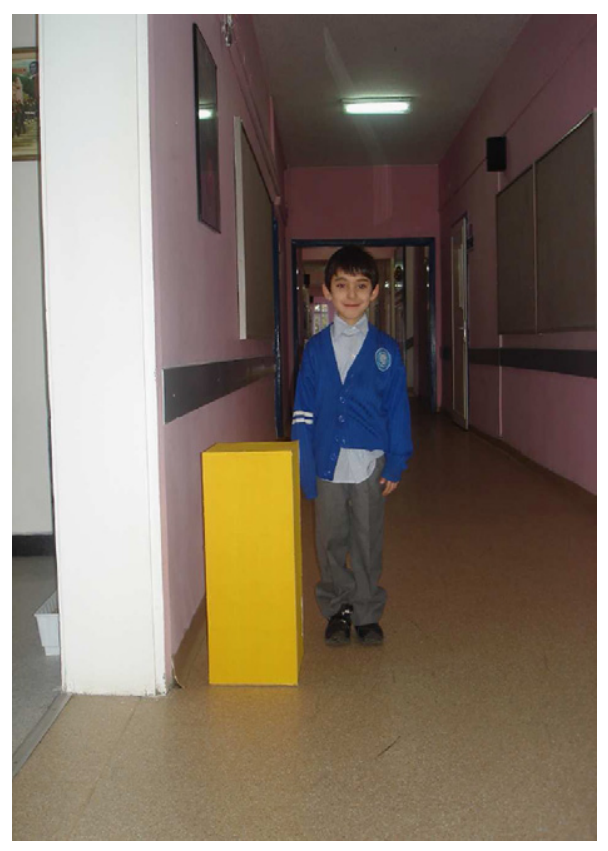

Fig. 5. View of the box with a seven-year-old male child.

change only the hues, while keeping the perceived lightnesses and saturations of colours the same, in order to understand the effect of hue. Samples of the Munsell colour system may provide more 


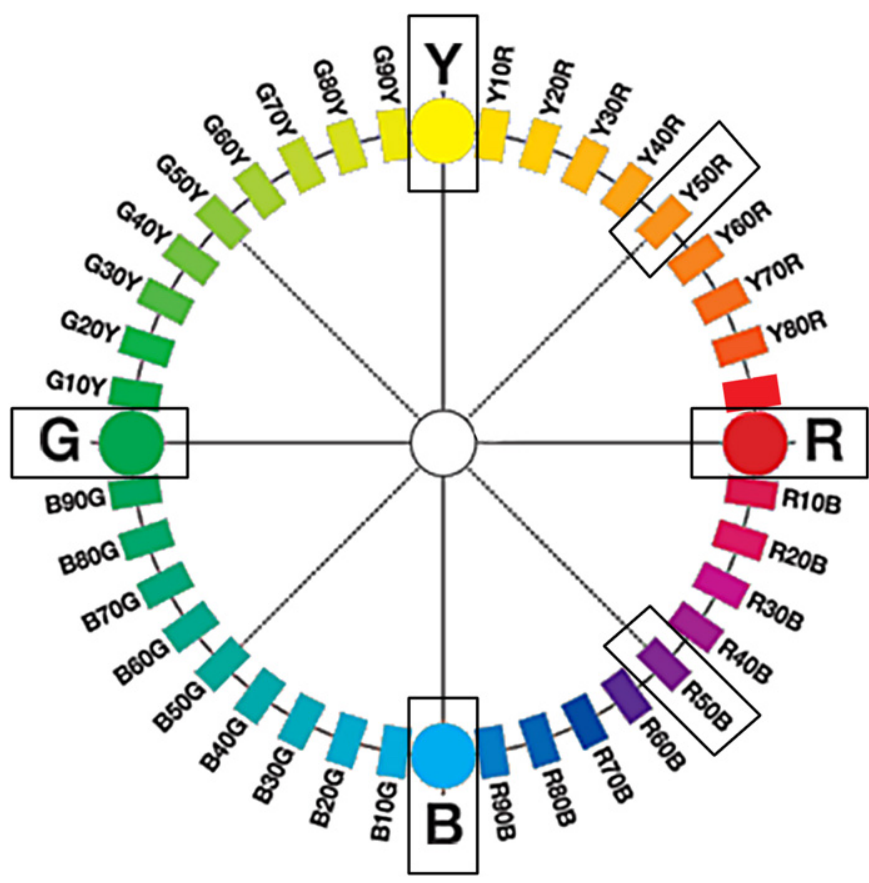

Fig. 6. NCS colour circle with selected colours.

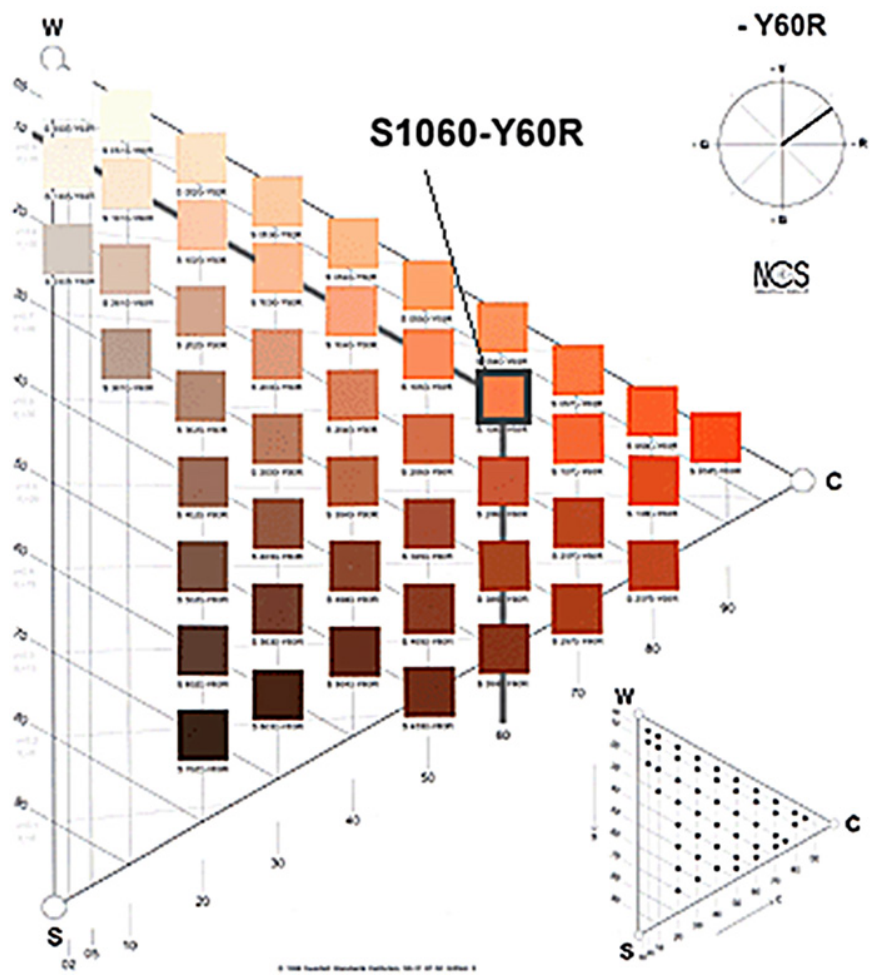

Fig. 7. NCS triangular chart showing the relationship of hue to white and black.

opportunities to obtain hues with same lightness and saturation, as in NCS this is not an easy task. The NCS was used in this study for two reasons:

a. Its samples were made to correspond to judgments of relative amounts of colour, white and black, that is, the judgment of perception.

b. In the colour production stage, it was possible to order paint with NCS colour codes.
The colours initially chosen for the experiment were the primary and the secondary colours of the NCS. After primary colours were selected (yellow, red, blue, green), all equidistant colours between them (orange, purple, turquoise and yellow green) were selected as secondary colours, as in Fig. 6. However, 'turquoise' and 'yellow green' were eliminated from the experiment sets, as they were not commonly used terms in seven and eight year old children's vocabulary, and hence relatively difficult for children to name. 'Turquoise' can be confusing both as a word and as a colour, as it contains both blueness and greenness. This makes for dispute whether it is a blue or a green [1]; the colour 'yellow green' has a similar problem. Hence the colours yellow, orange, red, purple, blue and green were tested in the final experiment.

Human vision does not provide an equal number of colours for each hue; for example, we discern more greens than yellows. For this reason, it is not always possible to have the same lightness and 'chromaticness' (saturation) for every hue. In order to control the lightness and chromaticness of the hues chosen, they were categorised according to their wavelengths. In Table 1, the groupings are long wavelength (yellow, orange and red) and short-middle wavelength (purple, blue and green). Within each of these groups the colours had the same lightness and chromaticness.

The final group in Table 1 is a single grey colour. This specific grey was selected by considering the existing surface colours of the experiment site. The vertical surfaces (walls) were white (S0500-N, 05\% Blackness, 95\% Whiteness) and very pale pink (S0520-R20B, 20\% Pink, 5\% Blackness, 75\% Whiteness). The horizontal surfaces (floors) were very pale beige (S2020-Y30R, $20 \%$ Beige, 20\% Blackness, 60\% Whiteness). Thus, the grey chosen for the experiment (S2500-N, 25\% Blackness, 75\% Whiteness) had a high enough value of blackness to be clearly distinguished from its surroundings.

There were three experiment sets, differing in the colour of the boxes. The colours corresponded to the groupings in Table 1 . In set 1 all boxes were grey, and sets 2 and 3 used all other colours. Sets 2 and 3 differed in how the colours were arranged within the route. It is important to note that different colour sets were needed in order to understand the effects of location in usage and memory of the boxes and the colours. A key determinant in this was the use of afterimage complementaries.

In human visual experience negative afterimages of nonluminous objects commonly occur in which the hues are complementary to those perceived in the original object ([24], p. 195). This may be experienced by gazing (staring fixedly) at a coloured object and then turning ones gaze to a neutral surface. The geometrical image of the object will continue to be 'seen' (hence the expression 'afterimage') but in a hue complementary to the original hue. This, therefore, is an important feature to be accommodated within the research, and for experiment sets 2 and 3, for each floor on the task route one pair of afterimage complementaries was selected. With reference to the NCS colour sequence shown in Fig. 6, the three pairs of complementary hues are yellow and purple, orange and blue, and red and green. For experiment set 2, each floor used a pair of afterimage complementary hues as follows. For the first floor purple and yellow was used, for the second floor orange and blue, and for the third, green and red. These are explicitly shown in Table 2. For set 3, the combination of floor level and colour pair was retained, but the order of colour within each pair was reversed. So, the first floor used yellow and purple, with similar reversal in the other floors. Again these are shown in Table 2.

The above explains the rationale for the complete floor/colour specification for the overall experiment. 
Table 1

Selected colours from NCS for the experiment.

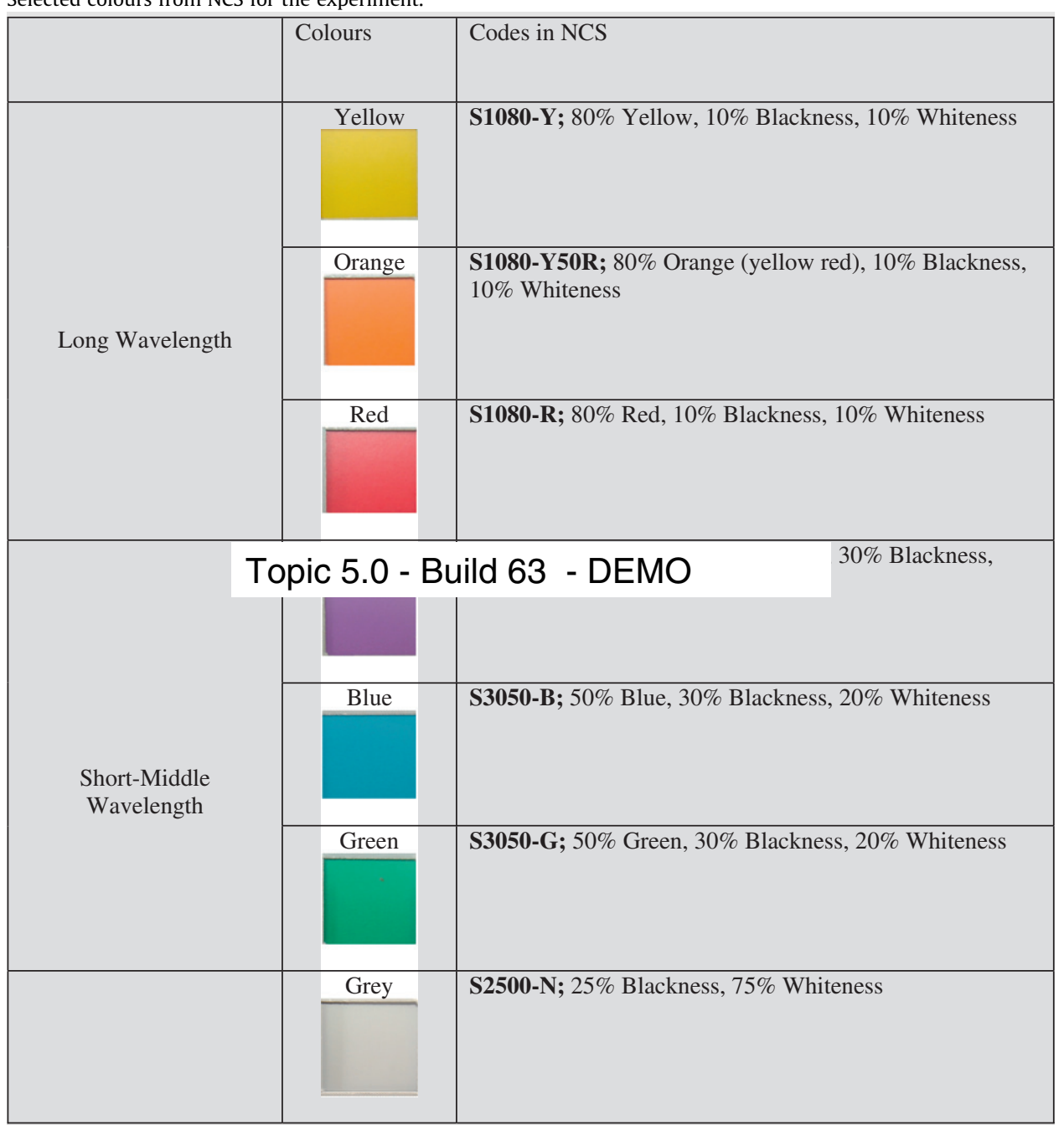

\subsection{Specifying the locations}

The site had both artificial and daylight illumination. The artificial lighting was kept active in the building during daylight hours. All experiments were conducted between 11:00 a.m.-13:30 p.m. At these hours, illuminance of all the floors was measured to ascertain the lighting situation in the building. The lamps used for the lighting were Standard Philips TL 20 fluorescent with 6200 colour temperature.

Colour sequences of experiment sets were decided according to illumination levels of the decision points. Illuminances of all floors were measured and an illuminance map of the building was created before the experiment. According to the map three of the decision points were more illuminated (had higher illuminance) than the others. So in the second experiment set, colours having short-middle wavelengths (purple, blue and green) were located at low illuminance points (50-100 lux) and colours having long wavelengths (yellow, orange and red) were located at high illuminance points (101-150 lux). In the third set, this systematic procedure was reversed, so that short-middle wavelength colours were located at high illuminance points and long wavelength colours at low illuminance points. All corridors had two boxes and two different illumination levels (low and high). The change was achieved by swapping the positions of the pair of boxes in that corridor.

\subsection{Phases of the experiment}

The study was conducted in four phases ([27], p. 141-146). In the first phase, a number of checks were made. First, the participants were tested for colour vision by using Ishihara's tests for colour-blindness. These tests comprise a series of plates designed to provide a quick and accurate assessment of colour vision deficiency of congenital origin [28]. In fact, none of the children were found to have colour vision problems. In addition, participants were asked about their general vision deficiencies. Again, no participants had vision problems. At this stage, then, all children were permitted to participate in the experiment. Finally, the children were asked some questions about any previous usage of and time spent in the building. This was in order to check whether they had any prior familiarity with the setting. Children who were identified as being familiar with the building were not included in the experiment.

In the second phase, children were taken on the experiment route individually. The tester informed the child about the test using this wording: "I am going to be leading you on a walk in this building today. On this walk you have to look around. Try to pay attention to some details in the building. When we get to the end of the walk, I will lead us back to here. This is our starting point. Then I will be asking you to lead me to the end point. Do you have any questions? This is our starting point, so let's go!". 
Table 2

Table showing the experiment sets 2 and 3, with their colour sequences.

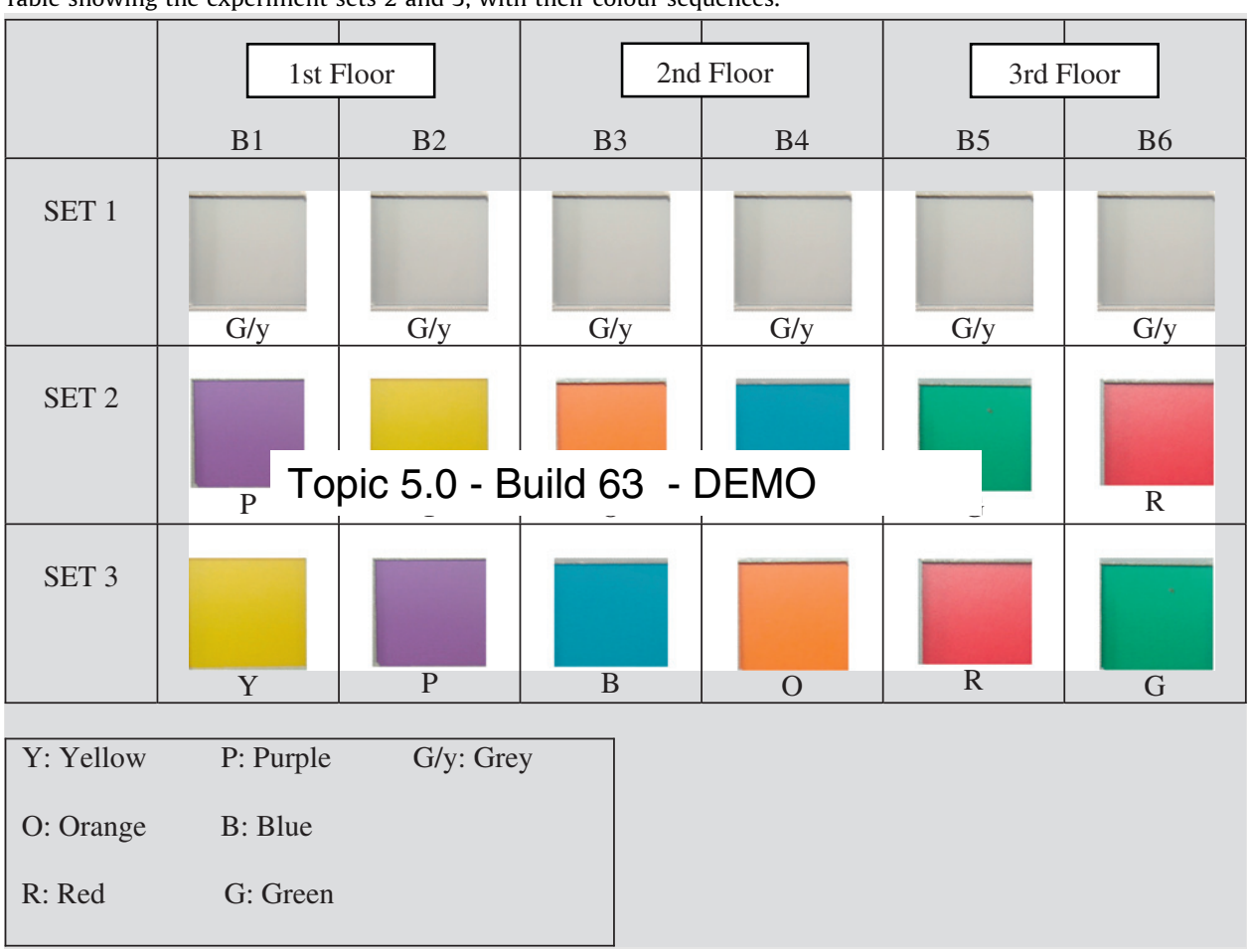

Y: Yellow P: Purple G/y: Grey, O: Orange B: Blue, R: Red G: Green.

Then the child was escorted on the route and she/he was led by the requisite grey or different coloured boxes according to the experiment sets. At the end of the route, the child was returned to the starting point, and then asked to lead the tester to the end point via the same route. While the child was leading the tester to the end point, the tester established that the child had paid attention to the original. This was done by asking each child the same two questions: "Why did you turn from here?" and "What is coming next?". The tester noted any hesitation points, and asked the reasons for the hesitation. The tester also noted the time it took to complete the route.

In the third phase, in-depth interviewing was conducted with the children. They were asked to describe the route verbally in order to record: their usage of colours, boxes and environmental design elements of the building, and their way of combining these elements with wayfinding and the process of route learning.

The responses, were recorded as data categorised in terms of seven issues: verbally describing the route accurately, mentioning colour in general, naming specific colours, mentioning the boxes in general, mentioning the location of specific boxes, naming the environmental design elements of the building, and using directional terms in the description of the route.

In the fourth phase, each child was shown a schematically drawn plan of the building with the route. Each child was asked verbally by the tester to recognise specific colours that were placed at specific decision points. In addition, each child was asked verbally to list all the colours used. Each child was asked on the route to test if any one of the colours was more memorable than the others.

The whole experiment was conducted over five consecutive days, with all four phases conducted sequentially for each child. The first experiment set with grey boxes was completed in one day, whereas the second and third experiment sets (coloured) took two days each. For each child, the phases of the experiment were conducted successively without any extensive break. It took approximately $20 \mathrm{~min}$ for one child to complete the experiment.

\section{Findings}

Statistical analyses were made in respect of the research hypotheses as stated in Section 3.

The specific procedures are described as follows, together with a discussion of the findings themselves.

\subsection{Effect of colour on children's route learning ability}

The effects of colour on children's route learning ability were evaluated and analysed under three headings:

- the accuracy of finding the end point,

- the time spent finding the end point and

- the identification of landmarks (boxes) as reference points.

First, the accuracy in route learning ability of three sample groups (three experiment sets termed set 1 , set 2 and set 3 ) was assessed by comparing the number of accurate responses.

Analysis of variance (ANOVA) was used as the statistical technique, since the approach was to analyse or divide the total variation into meaningful components. When random samples of size $n$ are selected from each of $k$ populations and the $k$ different populations are classified on the basis of a single criterion such as different treatments or groups, One-way ANOVA was used ([29], p. 462-63) and results from this indicated that there is a significant difference between sample groups in the accuracy of finding the end point $(F=24.207, p=0.000)$. In order to identify which sample group differed from the others, the Sheffe type Post Hoc 
Comparison Test was used [30]. This test examines sub-groups formed by various combinations of the sample groups, rather than just pair wise comparisons. The test results indicated that set 1 differed significantly from sets 2 and 3 . However, no significant difference was found between sets 2 and 3 . Set 1 , of course, was the grey set, whereas both sets 2 and 3 were coloured sets.

So, the statistical analyses verified the first hypothesis that colour has a significant effect on the ability of children accurately to find the end point of a route.

The hypothesis was further supported by the data for participants' hesitation values during the route finding process. The one-way ANOVA analysis again showed a significant difference between groups, in their amount of hesitations during the route finding process $(F=24.207, p=0.000)$, with set 1 significantly different from sets 2 and 3. Children hesitated less on the route with coloured boxes.

Second, the data were analysed for the time spent during the route finding process. This analysis also revealed differences between the experiment sets. Recorded time spent was categorised under the three time intervals: 30-60, 60-90 and 90- 120 seconds. The recorded fastest time was $42 \mathrm{~s}$ and the slowest was $118 \mathrm{~s}$. A significant difference was found between sets in the time spent $(F=103.062, p=0.000)$, this difference again being for the grey set 1 as compared to the coloured sets 2 and 3 . Children found their way faster on the route with coloured boxes.

The third analysis related to the use of boxes as reference points by using children's verbal descriptions of the route. Yet again, a significant difference between sample groups was found (set 1 compared with sets 2 and 3 ) when using the boxes as reference points within the verbal description of the route $(F=58.932, p=0.000)$. On set 1 's route with grey boxes, children did not use the boxes as reference points in their verbal descriptions, in contrast to their using sets 2's and 3's coloured boxes as verbal reference points.

Within the children's verbal description phase, an analysis was also made of the use of directional terms (right-left). Using the ANOVA test, a significant difference was found between sample groups in their verbal usage of the directional terms $(F=5.106$, $p=0.008)$.

It was only children from set 1 that used directional terms in their verbal descriptions, whereas the children from sets 2 and 3 always used colours and boxes in preference to directional terms. The analysis showed that, there is a significant effect of colour on the use of directional terms.

Children's usage of the boxes while actually walking on the route was also analysed and compared. Again a significant difference was found between sample groups, in their use of boxes as reference points while finding their way $(F=318.807$, $p=0.000$ ), and again this was for set 1 compared with sets 2 and 3 . While children were walking on a coloured route, they referred to the boxes as reference points more than they did on the grey route. This analysis shows the importance of the effect of using colour when using landmarks (boxes) as reference points in route learning processes.

All the analyses of data under the first hypothesis showed the important role of colour, in that without exception significant differences were found between the grey set 1 compared with the coloured sets 2 and 3. This leads to the conclusion that colour is a dominant factor in all aspects of children's route learning ability.

\subsection{Relationship between different hues of colour in their contribution to route learning ability}

The chi-square goodness-of-fit test analysis was used to compare different colours in their contribution to children's route
Table 3

Frequency of memorability of the colours.

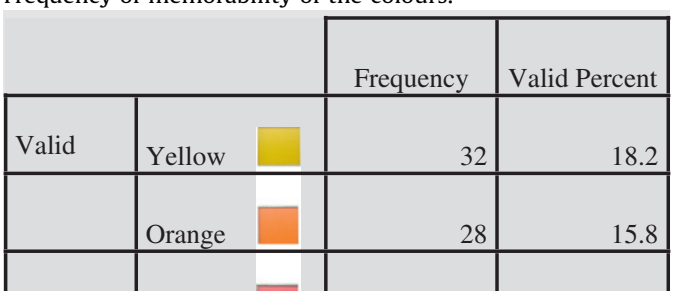

Topic 5.0 - Build 63 - DEMO

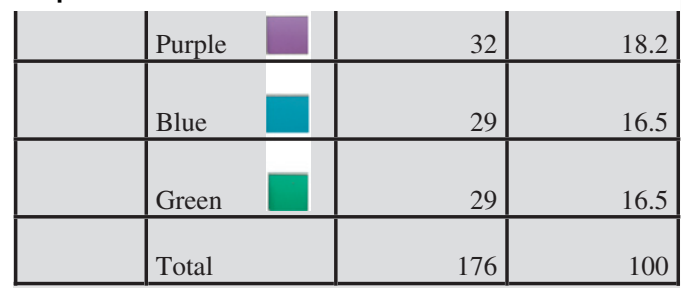

learning ability, by comparing the memorability of the colours in the experiment. The chi-square goodness-of-fit test is a nonparametric test used for multinomial frequency distribution, in cases of more than two points on the scale [29].

In this aspect of the study, the attention is on the frequency distribution of cases across a wide range of categories of variable formed by the six colours used in the experiment. As shown in Table 3, no significant relationship or difference was found between different hues of colour in their memorability $\left(x^{2}=1.059, d f=5, p=0.958\right)$. The second hypothesis, that of a significant effect of different hues of colour on childrens' route learning ability, was not verified.

The effects of wavelength of the colours used were then assessed. The chi-square goodness-of-fit test was applied to the children's memorability of a group of colours and on the usability of this group of colours. The data were grouped under the two categories of long (yellow, orange, red) and short-middle wavelengths (blue, purple, green). No significant effect of wavelength on colour memory was found $\left(x^{2}=0.091, d f=1\right.$, $p=0.763$ ). The test further showed no significant effect of wavelength on usability of colours within the verbal description of a route $\left(x^{2}=0.000, d f=1, p=1.000\right)$. Hence the warmth (long wavelengths) or coldness (short-middle wavelengths) of colour did not affect either memorability or usage in the verbal descriptions.

\subsection{Relationship between the colours and their locations in route learning}

Testing the third hypothesis, required data to be analysed from the fourth phase of the experiment, which related to the recognition of colours in their specific locations. The ability to identify correctly the colours of boxes was assessed by comparing the numbers of correct identifications (observed numbers), using the chi-square goodness-of-fit test.

The test showed a significant difference between colours in terms of their correct location identifications $\left(x^{2}=11.412, d f=5\right.$, $p=0.044$ ) as shown in Table 4 . The number of participants who remembered the colours in their correct places for both sets was statistically analysed. For instance, participant total for remembering yellow was obtained from the sum of the participant number remembering yellow in box 2 for set 2 and the participant number remembering yellow in box 1 for set 3 . This formed the basis of the statistics for the remembrance of the colour yellow in its correct location. The results showed that children remembered 
Table 4

Frequency of correct location and identification of colours.

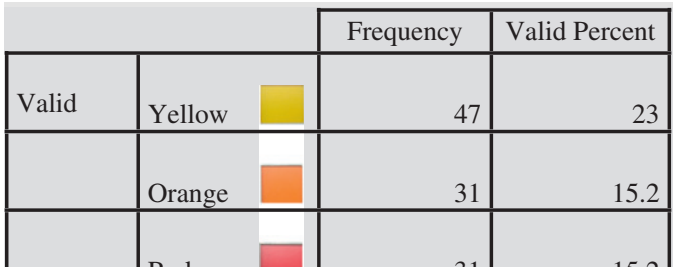

Topic 5.0 - Build 63 - DEMO

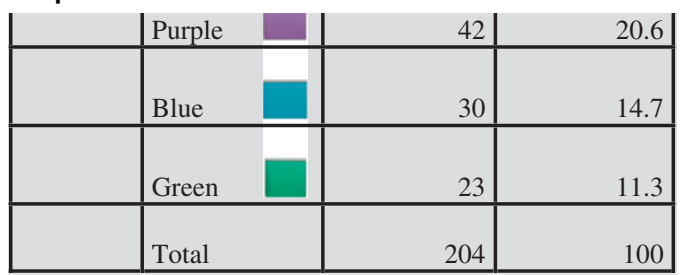

Table 5

Frequency of recognizing the specific sequence of colours.

\begin{tabular}{lcc}
\hline & Frequency & Valid percent \\
\hline Valid & & \\
Inaccurate & 59 & 86.8 \\
Accurate & 9 & 13.2 \\
Total & 68 & 100.0 \\
\hline
\end{tabular}

Table 6

Frequency of correct colour and identification of boxes.

\begin{tabular}{lcc}
\hline & Frequency & Valid percent \\
\hline Valid & & \\
Box 1 & 49 & 24.0 \\
Box 2 & 40 & 19.6 \\
Box 3 & 37 & 18.1 \\
Box 4 & 24 & 11.8 \\
Box 5 & 23 & 11.3 \\
Box 6 & 31 & 15.2 \\
Total & 204 & 100.0 \\
\hline
\end{tabular}

the location of the first and the second (yellow and purple) colours more accurately than the other colours.

However, as far as the specific sequence of colours on the route was concerned, as Table 5 shows, this was not recognized by a significant percentage of the children.

A significant difference was found between boxes in terms of their correct colour identifications $\left(x^{2}=14.706, d f=5, p=0.012\right)$ as shown in Table 6. A statistical analysis was then made of the number of participants who remembered the correct colours of the boxes for both of the sets 2 and 3. For example, the participant total for box 1 was obtained by summing the participant number remembering box 1's colour (purple) in set 2 and the number remembering box 1's colour (yellow) in set 3 . This gave the remembrance for the colour of box 1 , and other boxes were treated similarly. The results showed that children remembered the colours of the first and the second boxes more accurately than the other boxes.

The correct identification of any specific colour and box was dependent on their order $\left(x^{2}=10.088, d f=2, p=0.006\right)$. The first and second colours seen on the route and the boxes from the ground floor were more correctly identified, when compared with the alternatives. Therefore, the accuracy of identification
Table 7

Frequency of correct identification of colours and boxes in relation with the floors.

\begin{tabular}{lcc}
\hline & Frequency & Valid percent \\
\hline Valid & & \\
Ground floor & 89 & 43.6 \\
1st floor & 61 & 29.9 \\
2nd floor & 54 & 26.5 \\
Total & 204 & 100.0 \\
\hline
\end{tabular}

Table 8

Frequency of colours as reference points in verbal description.

\begin{tabular}{|c|c|c|c|}
\hline & & Frequency & Valid Percent \\
\hline \multirow[t]{2}{*}{ Valid } & Yellow & 37 & 21.3 \\
\hline & Orange & 26 & 14.9 \\
\hline & & & \\
\hline
\end{tabular}

Topic 5.0 - Build 63 - DEMO

\begin{tabular}{|l|l|r|r|} 
& Purple & 45 & 25.9 \\
\hline & & 23 & \\
& Blue & 19 & 13.2 \\
\hline & Green & 174 & 10.9 \\
\hline & Total & 100 \\
\hline
\end{tabular}

decreased with distance from entry that is with the order of appearance on the route. The data are given in Table 7.

In addition to the preceding analyses, data from children's verbal descriptions of the experiment route were analysed in respect to the colours and boxes mentioned above in order to understand the effects of colour and box number in their usage as reference points. According to the two analyses, there are significant differences both between colours $\left(x^{2}=16.897, d f=5\right.$, $p=0.005)$, Table 8 , and between boxes $\left(x^{2}=15.934, d f=5\right.$, $p=0.007$ ), Table 9 , in their usage as reference points within the verbal description process. Children mentioned the first and second colours and the first and second boxes more than the other colours and boxes, when making their verbal description. Further, their verbal use of specific colours and specific boxes was also dependent on their floor locations $\left(x^{2}=15.207, d f=2, p=0.000\right)$. The first and the second colours and the boxes from the ground floor were used more than the others and the usage of them decreased with increasing floor level, as shown in Table 10. These statistical analyses verified the third hypothesis indicating a significant relationship between colours and their locations in route learning.

Finally, an assessment was made of the effects of colour wavelength on the correct identifications of colour. The latter were assessed by comparing the number of correct identifications by children on the chi-square goodness-of-fit test. It was found that there is no significant effect of wavelength on the correct identification of colours $\left(x^{2}=0.961, d f=1, p=0.327\right)$. Again, the warmth (long wavelengths) and coldness of colour (short-middle wavelength) did not affect the accuracy of identification of the colours at their specific locations.

\subsection{Effect of gender on route learning}

The final question related to gender. To determine if there was a significant relationship between the gender of children and their 
Table 9

Frequency for boxes as reference points in verbal description.

\begin{tabular}{lcc}
\hline & Frequency & Valid percent \\
\hline Valid & & \\
Box 1 & 36 & 19.8 \\
Box 2 & 45 & 24.7 \\
Box 3 & 31 & 17.0 \\
Box 4 & 19 & 10.4 \\
Box 5 & 20 & 11.1 \\
Box 6 & 31 & 17.0 \\
Total & 182 & 100.0 \\
\hline
\end{tabular}

Table 10

Frequency for colours and boxes in verbal descriptions of the experiment route in relation with the floors.

\begin{tabular}{lcc}
\hline & Frequency & Valid percent \\
\hline Valid & & \\
$\quad$ Ground floor & 82 & 47.1 \\
1st floor & 49 & 28.2 \\
2nd floor & 43 & 24.7 \\
Total & 174 & 100.0 \\
\hline
\end{tabular}

accuracy in the route learning process, chi-square analysis tests were conducted. Sample groups were analysed separately at first, and then the relationship was analysed in total. The analyses gave consistent results. No significant relationship was found between gender and accuracy for the route learning process, whether separately in experiment sets 1,2 , or 3 or in the total $\left(x^{2}=1.758\right.$, $d f=1, p=0.185 ; x^{2}=0.926, d f=1, p=0.336 ; x^{2}=0.068, d f=1$, $p=0.794$ and $x^{2}=1.313, d f=1, p=0.252$; respectively).

So the fourth hypothesis was not verified by any of the chisquare tests, and, therefore, gender did not affect the accuracy of the route learning process.

\section{Conclusions}

Various aspects of the possible contribution of colour to children's wayfinding performance in school environments, including differences between colours in terms of their remembrance and usability in the route learning process were explored at Ankara University Private High School in Ankara, Turkey. The literature survey indicated that colour could be expected to affect route learning performance $[1,6,22]$ and results of the statistical tests confirmed this, showing various specific effects.

It was found that memorability is not significantly related to different hues of colour. However, a significant difference was found between colours and landmarks, in terms of identification of correct locations. Also, the accuracy of such identification was found to decrease with distance along the route.

Contrary to previous studies [31-33], no gender difference was found in route learning performance, both genders performing equally accurately.

For most young children, pre-school or primary school is the first public place they use, and the nature and quality of these environments affect student learning and behaviour [34]. Therefore, it is important to analyse carefully the type of environment provided for children in schools since they spend different amounts of time at their schools at different ages. As is obvious from the findings, coloured design elements within the building can act as key points and benefit wayfinding, in contrast to neutral-coloured elements.

The results of this study provide data for designing more legible and pleasant children's environments. Architects, interior architects, environmental planners, sign makers, educators and parents should communicate and work together for providing safe, functional and aesthetically pleasing environments for young children. Findings from this study can be beneficial to professionals who are not only dealing with colour and its contribution to design, but also to those involved in developing children's environments. Pre-school and primary school administrators can also benefit from the findings of this study to provide legible environments for children.

\section{References}

[1] Dalke H, Little J, Niemann E, Camgöz N, Steadman G, Hill S, et al. Colour and lighting in hospital design. Optics \& Laser Technology 2005;38:343-65.

[2] Cornell EH, Heth CD, Kneubuhler Y, Sehgal S. Serial position effects in children's route reversal errors: implications for police search operations. Applied Cognitive Psychology 1996;10:301-26.

[3] Lehnung M, Haaland VO, Pohl J, Leplow B. Compass-versus finger-pointing tasks: the influence of different methods of assessment on age-related orientation performance in children. Journal of Environmental Psychology 2001;21:283-9.

[4] Lehnung M, Leplow B, Haaland VO, Mehdorn M, Ferstl R. Pointing accuracy in children is dependent on age, sex and experience. Journal of Environmental Psychology 2003;23:419-25.

[5] Heth CD, Cornell EH, Alberts DM. Differential use of landmarks by 8-and 12 -year-old children during route reversal navigation. Journal of Environmental Psychology 1997;17:199-13.

[6] Osmann PJ, Wiedenbauer G. The representation of landmarks and routes in children and adults: a case study in a virtual environment. Journal of Environmental Psychology 2004;24:347-57.

[7] Bell S. Spatial cognition and scale: a child's perspective. Journal of Environmental Psychology 2002;22:9-27.

[8] Orr DW. Ecological literacy: education and the transition to a post-modern world. New York: State University of New York Press; 1992.

[9] Golledge RG. Wayfinding behaviour: cognitive mapping and other spatial processes. London: The Johns Hopkins University Press; 1999.

[10] Arthur P, Pasini R. Wayfinding: people, signs, and architecture. New York: McGraw-Hill Book Company; 1992.

11] Giuliani RW. Universal Design New York. New York: Mayor Publication; 2001

[12] Passini R. Wayfinding in architecture. New York: Van Nostrand Reinhold; 1984.

[13] Pollett D, Haskell P. Sign systems for libraries: solving the wayfinding problem. In: Levine D, editor. Universal design New York, Vol. 2. New York: Idea Publications; 1979. p. 54-74.

[14] Hunt E, Waller D. Orientation and wayfinding: A review. (ONR technical report N00014-96-0380). Arlington, VA: Office of Naval Research; 1999

[15] Matthews MH. Environmental cognition of young children: images of journey to school and home area. Transactions of the Institute of British Geographers 1984;9(1):89-105.

[16] Hill K. The psychology of lost. Ottawa, Canada: National SAR Secretariat; 1998

[17] Ambrose GV. Sighted children's knowledge of environmental concepts and ability to orient in an unfamiliar residential environment. Journal of Visual Impairment \& Blindness 2000;94(8):509-21.

[18] Osmann PJ, Fuchs P. Wayfinding behaviour and spatial knowledge of adults and children in a virtual environment: the role of landmarks. Experimental Psychology 2006;53(3):171-81.

[19] Cubukcu E, Nasar JL. Relation of physical form to spatial knowledge in largescale virtual environments. Environment and Behaviour 2005;37(3):397-17.

[20] Cornell EH, Sorenson A, Mio T. Human sense of direction and wayfinding Annals of the Association of American Geographers 2003;93(2):399-425.

[21] Janzen G. Memory for object location and route direction in virtual large-scale space. The Quarterly Journal of Experimental Psychology 2006:59(3):493-508.

[22] Read MA. Use of colour in child care environments: application of colour for wayfinding and space definition in Alabama child care environments. Early Childhood Education Journal 2003;30(4):233-9.

[23] Spence I, Wong P, Rusan M, Rastegar N. How colour enhances visual memory for natural scenes. Psychological Science 2006;17(1):1-6.

[24] Agoston GA. Color theory and its application in art and design, 2nd ed.. Berlin : Springer-Verlag; 1987

[25] Fehrman KR, Fehrman C. Color: the secret influence. New Jersey: PrenticeHall; 2000.

[26] Hard A, Sivik L. A theory of colors in combination-a descriptive model related to the NCS color-order system. Color Research and Application $2001 ; 26(1): 4-28$.

[27] Helvacioğlu, E. Colour contribution to children's wayfinding in schoo environments [dissertation]. Ankara (Turkey): Bilkent University, 2007. 
[28] Ishihara S. Ishihara's tests for colour-blindness. Japan: Kanehara Medical Publishing Co. Ltd.; 1975.

[29] Walpole RE, Myers RH, Myers SL. Probability and statistics for engineers and scientists, 6th ed.. New Jersey: Prentice Hall; 1998.

[30] Argyrous G. Statistics for research: with a guide to SPSS. London: SAGE Publications; 2005.

[31] Lawton CA, Charleston SI, Zieles AS. Individual- and gender-related differences in indoor wayfinding. Environment and Behaviour 1996;28(2):204-19.
[32] Schmitz S. Gender differences in acquisition of environmental knowledge related to wayfinding behaviour, spatial anxiety and self-estimated environmental competencies. Sex Roles 1999;41:71-93.

[33] Galea LAM, Kimura D. Sex differences in route-learning. Personality and Individual Differences 1993;14(1):53-65.

[34] Wilson R. Environmental education: a sense of place. Early Childhood Education Journal 1997;24(3):191-4. 